\title{
The case for surgery of the injured spine in the management of traumatic cord injuries
}

\author{
I. David Kaye ${ }^{1}$ - Alex R. Vaccaro ${ }^{1}$
}

Received: 7 December 2017 / Revised: 7 December 2017 / Accepted: 27 December 2017

(c) International Spinal Cord Society 2018

\begin{abstract}
Spinal cord injury can be a life-altering trauma for patients and can be costly to patients and society alike. Generally recognized as biphasic, these injuries have both primary and secondary drivers. Although the primary insult is largely unavoidable, prevention of secondary injury mechanisms - and the resultant cascade- has been a target of substantial research. Continued spinal cord compression has been recognized as one of several deleterious secondary mechanisms, and decompressive and stabilization surgery has been routinely used for neuroprotection in this setting. Numerous biomechanical and animal studies have confirmed its potential utility. More recently, several high-quality randomized trials have concluded that early surgery for spinal cord injury improves rates of recovery when compared with delayed or nonoperative management. Herein, we argue that early surgery for spinal cord injury with continued cord compression offers significant benefit and should be undertaken when not contraindicated.
\end{abstract}

With a worldwide incidence of 3.6 to 195.4 patients per million [1] and approximately 12,500 new cases in the United States annually [2], traumatic SCI (TSCI) can be physically and physiologically devastating on an individual level, and financially burdensome on a societal one. Therapies aimed at mitigating the untoward consequences of TSCI are continually being explored. Surgery is one of those modalities and increasing evidence is mounting that early intervention improves outcomes compared with late or nonoperative management.

Neurologic injury following TSCI occurs by both primary and secondary mechanisms. The primary injury, caused by rapid spinal cord compression, shear, and contusion, precipitates a cascade of events culminating in the secondary injury. These secondary mechanisms include physiological, biochemical, immunological, and cellular changes in the injured cord [3-6]. Continued spinal cord compression is another potential source of secondary injury

$\triangle$ I. David Kaye

David.kaye@rothmaninstitute.com

1 Department Orthopedic and Neurological Surgery Rothman Institute, Thomas Jefferson University Hospital, 925 Chestnut Street, Philadelphia, PA 19107, USA and decompressive and stabilization surgery aims to prevent this type of damage.

Several animal studies have suggested that SCI is correlated with time duration of spinal cord compression, and that early decompression may be neuroprotective [7-10]. In one of the highest quality studies specifically evaluating the relationship between timing of spinal cord decompression and the potential for recovery following surgery, Carlson et al. [9] compared the neurological recovery of 16 dogs that underwent sustained spinal cord compression for either 30 or $180 \mathrm{~min}$, followed by removal of the compressive loads. Somatosensory-evoked potentials (SSEPs) monitoring, which were lost during the compressive period, recovered during a $60 \mathrm{~min}$ post-compressive period for the dogs in the $30 \mathrm{~min}$ cohort, but not in the $180 \mathrm{~min}$ cohort. This SSEP recovery in the $30 \mathrm{~min}$ cohort was sustained 28 days post injury. Functional motor recovery was also significantly better in the $30 \mathrm{~min}$ group compared with the $180 \mathrm{~min}$ cohort. The authors suggest that the secondary injury mechanisms related to prolonged tissue displacement can be mitigated by spinal cord decompression and prolonged tissue displacement times can allow propagation of these secondary mechanisms making recovery more difficult.

These findings have been multiply corroborated and the consensus in the spine literature is that preclinical studies have confirmed the benefit of timely decompression for SCI with continued compression [7, 8, 10]. However, early 
clinical studies in humans were more equivocal regarding improved outcomes for surgery as opposed to nonoperative management in this setting.

Guttman [11] was an early advocate for nonoperative management of SCI and recommended postural reduction techniques to help with recovery. Frankel et al. [12] reported their series of 612 patients who had sustained SCI and were managed using postural reduction at the National Spinal Injuries Centre at Stoke Mandeville Hospital in England. Managed nonoperatively, 29\% of Frankel A patients improved at least one grade during their hospital stay. This has served as a benchmark for spontaneous neurological recovery following nonoperative management of SCI.

Some studies from the late 1980s and early 1990s found no differences in the neurological outcomes of operatively and nonoperatively managed patients [13-16]. However, one of those studies [15] was a retrospective review of prospectively collected data from the NASCIS II trial, which was not designed to study differences in surgical and nonsurgical outcomes, and another [16] was a prospective but non-randomized trial and actually showed a significant mortality benefit to surgery, but no difference in neurological recovery. Similarly, prospective studies by Vaccaro et al. [17] and Waters et al. [18] were unable to document a beneficial effect of the timing of surgical decompression. However, all patients in the study of Water et al. [18] underwent delayed surgical intervention and even the patients who underwent early surgery in the cohort of Vaccaro et al. [17] may not have been operated on for as long as $72 \mathrm{~h}$ post injury.

Studies from the early 2000s began to more convincingly demonstrate a benefit to surgical intervention for SCI. Papadopoulos et al. [19] prospectively compared the results of operative and nonoperative management of 91 patients with cervical SCI. Only 25\% (6/25) of the nonoperative cohort experienced neurological improvement (consistent with earlier reports), compared with over 50\% (39/66) of the decompressed patients, including 12\% (vs 0\%) of patients in this cohort with Frankel A or B grades who improved to Frankel D or E.

Although all nonoperative management studies have been limited to Level III evidence (retrospective series) and the majority of studies comparing operative and nonoperative management had been limited to Level II (prospective, nonrandomized, or low-quality randomized, prospective) and Level III studies, a meta-analysis of the literature from 1966 to 2000 concluded that early decompression resulted in better outcomes compared with both conservative $(P<$ $0.001)$ and late management $(P<0.001)$ [20].

Finally, in 2012, a well-designed, multicenter, prospective study evaluated the effects of early $(<24 \mathrm{~h})$ vs late $(>24 \mathrm{~h})$ surgery in the setting of SCI [21]. The STASCIS
[21] (Surgical Timing in Acute Spinal Cord Injury Study) included 313 patients with acute cervical SCI, 182 who underwent early surgery $(<24 \mathrm{~h})$, and 131 who underwent late surgery $(>24 \mathrm{~h})$ and who were followed for 6 months. This study definitively demonstrated the benefits of early surgery and found that $19.8 \%$ of the early surgery cohort improved $\geq 2$ American Spinal Injury Association (ASIA) grades compared with only $8.8 \%$ of those who underwent later surgery. Regression analysis demonstrated that controlling for preoperative neurological status and steroid administration, the odds of at least a 2 grade ASIA Impairment Scale (AIS) improvement were 2.8 times higher for those undergoing early vs late surgery (odds ratio $=$ $2.83,95 \%$ confidence interval:1.10-7.28).

SCI has a biphasic mechanism and, although the primary injury may be irreversible and unpreventable, the secondary injury may be attenuated with interventions including surgery. Animal studies have lead to a better understanding of the pathophysiology of SCI and have established a rationale for early surgical intervention. With more advanced surgical techniques and spinal instrumentation, recent studies have confirmed the benefits of early surgery for SCI [21-23]. Riew et al. [24] in a commentary on the increasing use of surgery for central cord syndrome [25] noted that with the widespread acceptance in the surgical community of early surgery in this setting, we may have reached a "tipping point" in SCI care such that early intervention is now so widely accepted that it may become the new standard of care. In light of the current evidence, unless there is a contraindication to early surgery, most patients should have early decompression.

\section{Compliance with ethical standards}

Conflict of interest :The authors declare that they have no conflict of interest.

\section{References}

1. Jazayeri SB, Beygi S, Shokraneh F, Hagen EM, RahimiMovaghar V. Incidence of traumatic spinal cord injury worldwide: a systematic review. Eur Spine J. 2015;24:905-18.

2. National Spinal Cord Injury Statistical Center. Facts and Figures at a Glance. Birmingham, Alabama: Univ. Alabama at Birmingham; 2015.

3. Tator $\mathrm{CH}$, Fehlings MG. Review of the secondary injury theory of acute spinal cord trauma with emphasis on vascular mechanisms. J Neurosurg. 1991;75:15-26.

4. Anderson DK, Hall ED. Pathophysiology of spinal cord trauma. Ann Emerg Med. 1993;22:987-92.

5. Wagner FC Jr., Stewart WB. Effect of trauma dose on spinal cord edema. J Neurosurg. 1981;54:802-6.

6. Emery E, Aldana P, Bunge MB, Puckett W, Srinivasan A, Keane RW, et al. Apoptosis after traumatic human spinal cord injury. J Neurosurg. 1998;89:911-20. 
7. Dolan EJ, Tator $\mathrm{CH}$, Endrenyi L. The value of decompression for acute experimental spinal cord compression injury. J Neurosurg. 1980;53:749-55.

8. Delamarter RB, Sherman J, Carr JB. Pathophysiology of spinal cord injury. Recovery after immediate and delayed decompression. J Bone Jt Surg Am. 1995;77:1042-9.

9. Carlson GD, Minato Y, Okada A, Gorden CD, Warden KE, Barbeau JM, et al. Early time-dependent decompression for spinal cord injury: vascular mechanisms of recovery. J Neurotrauma. 1997;14:951-62.

10. Dimar JR II, Glassman SD, Raque GH, Zhang YP, Shields CB. The influence of spinal canal narrowing and timing of decompression on neurologic recovery after spinal cord contusion in a rat model. Spine. 1999;24:1623-33.

11. Guttmann L. Initial treatment of traumatic paraplegia and tetraplegia. Harris P, editor. Spinal Injuries Symposium. Edinburgh: Royal College of Surgeons, 1963;80-92.

12. Frankel HL, Hancock DO, Hyslop G, Melzak J, Michaelis LS, Ungar GH, et al. The value of postural reduction in the initial management of closed injuries of the spine with paraplegia and tetraplegia. I. Paraplegia. 1969;7:179-92.

13. Dall DM. Injuries of the cervical spine: II. Does anatomical reduction of the bony injuries improve the prognosis for spinal cord recovery? S Afr Med J. 1972;46:1083-90.

14. Harris P, Karmi MZ, McClemont E, Matlhoko D, Paul KS. The prognosis of patients sustaining severe cervical spine injury (C2C7 inclusive). Paraplegia. 1980;18:324-30.

15. Duh MS, Shepard MJ, Wilberger JE, Bracken MB. The effectiveness of surgery on the treatment of acute spinal cord injury and its relation to pharmacological treatment. Neurosurgery. 1994;35:240-8. discussion248-249

16. Tator CH, Duncan EG, Edmonds VE, Lapczak LI, Andrews DF. Comparison of surgical and conservative management in 208 patients with acute spinal cord injury. Can J Neurol Sci. 1987;14:60-69.

17. Vaccaro AR, Daugherty RJ, Sheehan TP, Dante SJ, Cotler JM, Balderston RA, et al. Neurologic outcome of early versus late surgery for cervical spinal cord injury. Spine. 1997;22:2609-13.

18. Waters RL, Adkins RH, Yakura JS, Sie I. Effect of surgery on motor recovery following traumatic spinal cord injury. Spinal Cord. 1996;34:188-92.

19. Papadopoulos SM, Selden NR, Quint DJ, Patel N, Gillespie B, Grube S. Immediate spinal cord decompression for cervical spinal cord injury: feasibility and outcome. J Trauma. 2002;52:323-32.

20. La Rosa G, Conti A, Cardal S, Cacciola F, Tomasello F. Does early decompression improve neurological outcome of spinal cord injured patients? Appraisal of the literature using a meta-analytical approach. Spinal Cord. 2004;42:503-12.

21. Fehlings MG, Vaccaro A, Wilson JR, Singh A, W Cadotte D, Harrop JS, et al. Early versus delayed decompression for traumatic cervical spinal cord injury: results of the Surgical Timing in Acute Spinal Cord Injury Study (STASCIS). PLoS ONE. 2012;7: e32037.

22. Wilson JR, Singh A, Craven C, Verrier MC, Drew B, Ahn H, et al. Early versus late surgery for traumatic spinal cord injury: the results of a prospective Canadian cohort study. Spinal Cord. 2012;50:840-3.

23. Umerani MS, Abbas A, Sharif S. Clinical outcome in patients with early versus delayed decompression in cervical spine trauma. Asian Spine J. 2014;8:427-34.

24. Riew KD, Kang DG. Central cord syndrome: is operative treatment the standard of care? Spine J. 2015;15:443-5.

25. Brodell DW, Jain A, Elfar JC, Mesfin A. National trends in the management of central cord syndrome: an analysis of 16,134 patients. Spine J. 2015;15:435-42. 